J. Clin. Chem. Clin. Biochem.

Vol. 25, 1987, pp. 177-181

C) 1987 Walter de Gruyter \& Co. Berlin - New York

\title{
Reflections on the Standardization of Total Bilirubin in Neonatal Serum
}

\author{
By B. G. Blijenberg, H. A. Roetering and B. Leijnse \\ Department of Clinical Chemistry, Academic Hospital Rotterdam-Dijkzigt, The Netherlands
}

(Received September 5/October 31, 1986)

\begin{abstract}
Summary: A study is described on the standardization of the determination of neonatal total bilirubin. A wide variation in results was shown in surveys held in The Netherlands and Germany and the reasons for this variation were sought. The suitability of commercial bilirubin standards and direct reading instruments, widely used in the neonatal field, was tested by comparing all measurements with those obtained with the candidate reference method. We found differences between the stated.values and those obtained by the reference method. However, a bias was also shown to exist between the results measured with the direct reading instruments and those obtained with the reference method, explaining at least qualitively, the variation seen in the surveys. In addition, problems in the calibration of the DuPont ACA are discussed.
\end{abstract}

\section{Introduction}

In previous articles we described our concern with the accuracy and the precision of the determination of the concentration of total bilirubin in neonatal serum $(1,2)$. For a number of reasons we decided to study in detail various analytical aspects of commonly used techniques. A very important reason is the availability now of the recently published candidate reference method for total bilirubin (3). It should be possible to study the state of the art in the neonatal field against the background of this technique.

Tab. 1. Information concerning the state of the art of the determination of neonatal bilirubin (total) in The Netherlands.

a. Methods in use

1. diazo methods

2. direct spectrometric methods with dilution

3. direct spectrometric methods without dilution

b. Calibration

1. commercial standards

2. ówn standards

3. factor

4. factor + standards

5. Hertz method

6. filter
In addition, we were involved in discussions on the results of surveys held in The Netherlands and the Federal Republic of Germany. The surveys indicate a high coefficient of variation mainly due to a lack of valid standardization (CV's $8-10 \%$ ). Finally, we wanted to re-evaluate our own calibration procedure for our DuPont ACA-NBIL method, which is a bichromatic method with buffer dilution (4).

The starting point of the study was the questionnaire on neonatal bilirubin which was included in a survey organized by the Dutch Foundation for Quality Assessment in Clinical Chemistry in February 1986. The most relevant practical information is given in table 1 .

The information given in table 1 led us to question the validity of the various standardization procedures.

\section{Materials and Methods \\ Materials}

The neonatal serum samples were from babies up to one week old. The samples were pooled to obtain a sufficient quantity for the study. The various specimens were collected over a period of two weeks, during which time they were stored at $-20^{\circ} \mathrm{C}$.

The adult serum samples (not pooled) were chosen at random Some of these were known to have an elevated conjugated bilirubin level. 
The bilirubin for our own standards was from Pfanstiehl (Reference Grade). The purity was checked and compared with SRM 916 from the National Bureau of Standards by the Dutch National Institute of Public Health (5).

Human albumin, purified, ORHA 20/21 was from Behringwerke AG. The bilirubin standards in human serum and in human albumin were prepared exactly according to the instructions described by Doumas et al. (3).

The following commercial preparations were used.

1. Dade Bilirubin-Control, lot No. BIC 972. A human albumin-based control material.

2. Boehringer Mannheim Precibil, lot No. 1-211. A human serum-based control material.

3. Beckman Ultimate Bilirubin Calibrators C4, C 8 and C20, lot Nos. C506056, C 506057 and C 506055 resp. Three human serum-based control materials.

4. DuPont ACA Liquid Bilirubin Calibrators, lot No. 011251 Three bovine serum-based materials intended for calibrating the ACA.

5. Control materials from the Dutch National Institute of Public Health: These bovine serum-based materials were validated according to a value assignment programme with 8 participants using the candidate reference method (11).

\section{Methods}

The candidate reference method for the determination of total bilirubin was applied for all serum samples: neonatal, adult and commercial as well as for the standard preparations (3). The control materials issued by the Dutch National Institute of Public Health (5) (see above) served as a check on the whole procedure.

Spectrophotometers were checked as described by Perry et al., i. e. wavelength calibration with a holmium oxide glass filter photometric accuracy with potassium dichromate solutions and photometric linearity with cobaltous ammonium sulphate solutions (6).

The Hertz method, which is a bichromatic measurement with buffer dilution, was applied as published by Hertz, Dybkaer \& Lauritzen (7), using the formula:

$$
c_{\text {bil }}=\mathrm{f}\left(21.6 \times \mathrm{A}_{466}-27.4 \times \mathrm{A}_{522}\right),
$$

where

$c_{b i l}$ represents the concentration of total bilirubin in $\mu \mathrm{mol} / 1$ and $f$ the dilution factor.

The direct reading bilirubin determinations were carried out with plane Hellma micro-cuvets equipped with a small glass plate which can be dipped into the cuvets leaving an optical path length of $0.87 \mathrm{~mm}$.

The DuPont ACA-NBIL was used according to the instruction of the manufacturer except for the calibration procedure (see Results and Discussion).

Terminology

Direct reading in this study means that the absorbance of the sample is measured without dilution.

\section{Results}

Because of the widespread popularity of commercial preparations, at least in The Netherlands, we started the study by checking the analytical data provided in the information sheets of the commercial products mentioned under Materials and Methods. This was done on three different days in triplicate using two methods i.e. the candidate reference method and the method of Hertz et al. We used only human preparations. We also analysed our own standards prepared with human albumin and in human serrum.

In table 2 all standard data are given, measured as well as stated.

With the data mentioned in table 2 we were able to calculate the accuracy of the neonatal serum determinations for a direct reading measurement. Direct reading instruments are based on a bichromatic measuring principle and are very popular in the neonatal field. Mostly the light absorption of the sample (serum) is measured directly at two wavelengths i.e. one for bilirubin and the other for correction for haemoglobin. We simulated this situation with our spectrophotometer by measuring absorbance at the commonly used wavelength combinations $461-551$ $\mathrm{nm}$ and $455-575 \mathrm{~nm}$. The following formula (or its equivalent for $455-575 \mathrm{~nm}$ ) was applied:

$$
\frac{\left(\mathrm{A}_{461}-\mathrm{A}_{551}\right)_{\text {sample }}}{\left(\mathrm{A}_{461}-\mathrm{A}_{551}\right)_{\text {standard }}} \times c_{\text {standard }}[\mu \mathrm{mol} / 1]
$$

Tab. 2. Values for standard bilirubin preparations.

\begin{tabular}{|c|c|c|c|c|}
\hline & $\begin{array}{l}\text { Reference } \\
\text { method } \\
\mu \mathrm{mol} / 1\end{array}$ & $\begin{array}{l}\text { Hertz } \\
\text { method } \\
\mu \mathrm{mol} / \mathrm{l}\end{array}$ & $\begin{array}{l}\text { Stated } \\
\text { value } \\
\mu \mathrm{mol} / \mathrm{l}\end{array}$ & 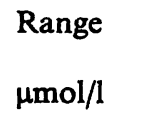 \\
\hline $\begin{array}{l}\text { Human albumin } \\
\text { (own) }\end{array}$ & 362 & 359 & & \\
\hline $\begin{array}{l}\text { Human serum } \\
\text { (own) }\end{array}$ & 359 & 368 & & \\
\hline $\begin{array}{l}\text { Dade Bilirubin- } \\
\text { Control }\end{array}$ & 325 & 322 & 340 & $\begin{array}{l}316-364 \\
\ldots\end{array}$ \\
\hline $\begin{array}{l}\text { Boehringer } \\
\text { Precibil }\end{array}$ & 277 & 280 & 300 & $246-354$ \\
\hline $\begin{array}{l}\text { Beckman } \\
\text { Ultimate } 4\end{array}$ & 65 & 67 & 68 & $67-70$ \\
\hline $\begin{array}{l}\text { Beckman } \\
\text { Ultimate C } 8\end{array}$ & 130 & 134 & 135 & $132-138$ \\
\hline $\begin{array}{l}\text { Beckman } \\
\text { Ultimate C } 20\end{array}$ & 318 & 333 & 332 & $326-338$ \\
\hline \multicolumn{5}{|c|}{ Sera Nat. Inst. Publ. Health } \\
\hline $\begin{array}{l}\text { P } 100 \text { BSA } \\
\text { P } 300 \text { BSA }\end{array}$ & $\begin{array}{r}99 \\
286\end{array}$ & & $\begin{array}{r}99 \\
290\end{array}$ & $\begin{array}{r}97-101 \\
287-293\end{array}$ \\
\hline
\end{tabular}
Only diazo results are mentioned for commercial sera. 
Table 3 shows the results of the calculations based on the absorbance measurements of the neonatal samples as well as the various bilirubin standards. The bilirubin data thus obtained can be compared with those obtained by applying the candidate reference method. For convenience the table shows the average deviations, calculated as a percentage, between the direct reading method results and the reference method results. Only the results for the combination $461-551 \mathrm{~nm}$ have been used, but similar results were found with the combination $455-575 \mathrm{~nm}$.

Tab. 3. Comparison of direct measurement technique with reference method.

Absorbance readings of 16 neonatal sera (range: $130-218 \mu \mathrm{mol} / \mathrm{l})$ and bilirubin preparations were taken at 461 and $551 \mathrm{~nm}$.

Calculation formula:

$\frac{\left(\mathrm{A}_{461}-\mathrm{A}_{551}\right)_{\text {sample }}}{\left(\mathrm{A}_{461}-\mathrm{A}_{551}\right)_{\text {standard }}} \times c_{\text {standard }}[\mu \mathrm{mol} / 1]$.

a. Average reference method values for 16 neonatal sera.

b. Average calculations based on diazo values for bilirubin preparations found with the reference method. Here $c_{\text {standard }}$ represents the value found with the reference method for the various bilirubin preparations.

c. Average calculations based on diazo values for bilirubin preparations given by the manufacturer. Here $c_{\text {standard }}$ represents the value given in the insert.

d. Percentage difference between $a$. and $b$.

e. Percentage difference between $a$. and $c$.

\begin{tabular}{llllll}
\hline $\begin{array}{l}\text { Bilirubin } \\
\text { preparations }\end{array}$ & $\begin{array}{l}\text { a. } \\
\mu \mathrm{mol} / \mathrm{l}\end{array}$ & $\begin{array}{l}\text { b. } \\
\mu \mathrm{mol} / 1\end{array}$ & $\begin{array}{l}\text { c. } \\
\mu \mathrm{mol} / 1\end{array}$ & $\begin{array}{l}\text { d. } \\
\%\end{array}$ & $\begin{array}{l}\text { e. } \\
\%\end{array}$ \\
\hline & 163 & & & & \\
Albumin & & 202 & & 24 & \\
Serum & & 186 & & 14 & \\
Dade & & 202 & 212 & 24 & 30 \\
Boehringer & & 174 & 189 & 7 & 16 \\
Beckman C20 & & 176 & 184 & 8 & 13 \\
\hline
\end{tabular}

Finally we considered the calibration of the DuPont ACA. This machine reads absorbance at 452 and $540 \mathrm{~nm}$ after dilution with buffer and calculates the results on the basis of stored calibration data. We routinely calibrate with serum samples from adult patients (sufficient sample volume!). Samples with elevated bilirubin levels are measured with the Hertz technique, which is easily applicable, and the results are used as set points for the ACA. This approach may seem ambiguous because it combines calibration with sera from adults with measurement of sera from neonates. However, it is our experience that the neonatal results thus obtained with the ACA correlate very well with those from our own diazo method. We therefore wanted to check for a similar correlation with the reference method. The results of 20 neonatal samples are given in figure 1 . The average ACA va- lues proved to be $164 \mu \mathrm{mol} / \mathrm{l}$ while the average reference method values were $167 \mu \mathrm{mol} / \mathrm{l}$. As a comparison we also measured these samples with the Hertz method, giving an average value of $180 \mu \mathrm{mol} / 1$. Figure 2 shows the data from 25 adult serum samples handled at the same way, i.e. ACA and Hertz, together with data from the above-mentioned neonatal samples. A comparable graph can be constructed with the reference method results on the $y$-axis i.e. we found a difference between adult and neonatal samples when applying the Hertz method. In other words, the Hertz method cannot be used as a calibration method for neonatal bilirubin. This surprising result will be studied in detail later.

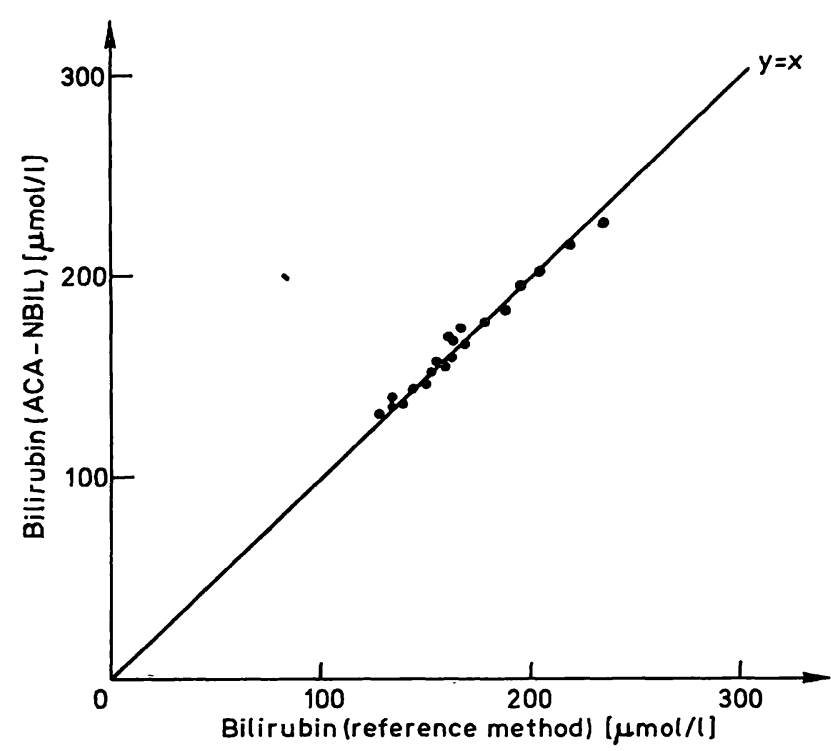

Fig. 1. Comparison of results obtained with the neonatal sera reference method and the ACA-NBIL.

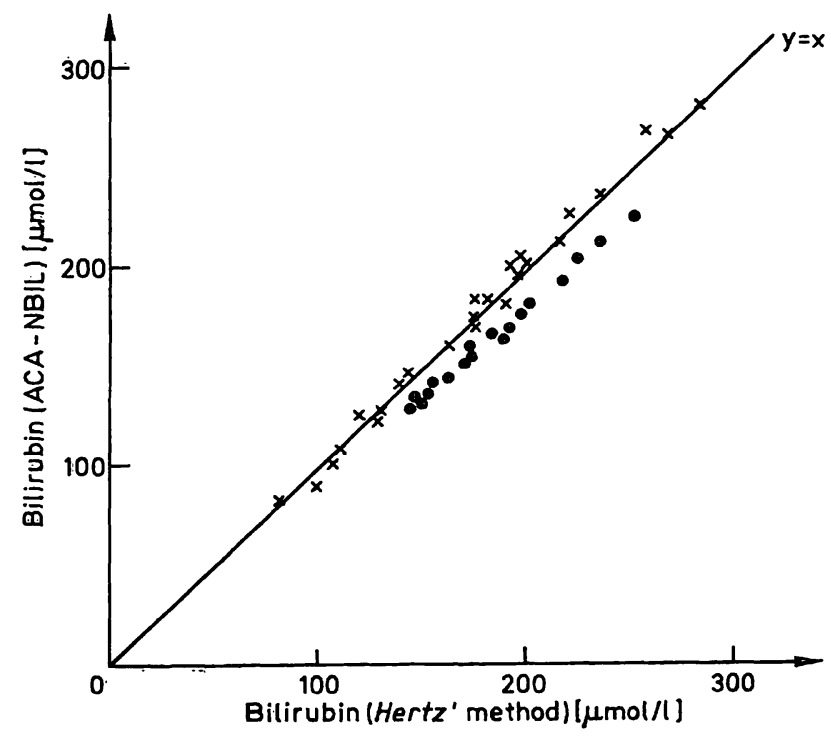

Fig. 2. Comparison of results obtained with the Hertz method and the ACA-NBIL, using neonatal $(0-0)$ and adult $(\chi-\chi)$ sera. 
The final part of the study concerned with application of the commercial serum samples mentioned above and the liquid bilirubin calibrators issued by DuPont. Table 4 shows the differences between the various diazo values and the ACA results, calibrated as shown in figure 1 and 2.

Tab. 4. Comparison of ACA bilirubin values (NBIL), reference method values and stated values.

Only diazo results are mentioned except for Dade Bilirubin Control. Calibration of ACA: see text.

\begin{tabular}{|c|c|c|c|c|}
\hline & $\begin{array}{l}\text { a. } \\
\text { Stated } \\
\text { value }\end{array}$ & $\begin{array}{l}\text { b. } \\
\text { Reference } \\
\text { method } \\
\text { found } \\
\mu \mathrm{mol} / 1\end{array}$ & $\begin{array}{l}\text { c. } \\
\text { ACA } \\
\text { value } \\
\text { found } \\
\mu \mathrm{mol} / 1\end{array}$ & $\begin{array}{l}\text { d. } \\
\text { Differ- } \\
\text { ence } \\
a-c \\
\%\end{array}$ \\
\hline Human albumin & & 362 & 328 & \\
\hline Human serum & & 359 & 327 & \\
\hline \multicolumn{5}{|c|}{ Dade Bilirubin-Control } \\
\hline 1. diazo value & 340 & 325 & & \\
\hline $\begin{array}{l}\text { 2. ACA-NBIl } \\
\text { value }\end{array}$ & 332 & & 292 & 12 \\
\hline $\begin{array}{l}\text { Boehringer } \\
\text { Precibil }\end{array}$ & 300 & 277 & 260 & 13 \\
\hline $\begin{array}{l}\text { Beckman } \\
\text { Ultimate C4 }\end{array}$ & 68 & 65 & 62 & 9 \\
\hline $\begin{array}{l}\text { Beckman } \\
\text { Ultimate C } 8\end{array}$ & 135 & 130 & 122 & 10 \\
\hline $\begin{array}{l}\text { Beckman } \\
\text { Ultimate C } 20\end{array}$ & 332 & 318 & 298 & 10 \\
\hline \multicolumn{5}{|c|}{ DuPont ACA Calibrator } \\
\hline $\begin{array}{l}\text { level } 1 \\
\text { level } 2 \\
\text { level } 3\end{array}$ & $\begin{array}{r}\left.26^{*}\right) \\
\left.162^{*}\right) \\
\left.342^{*}\right)\end{array}$ & $\begin{array}{r}21 \\
142 \\
287\end{array}$ & $\begin{array}{r}20 \\
138 \\
285\end{array}$ & $\begin{array}{l}23 \\
15 \\
17\end{array}$ \\
\hline
\end{tabular}

*) After completion of the work and the manuscript, the manufacturer reassigned these values, which are now 22,139 and $291 \mu \mathrm{mol} / 1 \mathrm{resp}$. This would result in differences $(a-c)$ of $9,<1$ and $2 \%$ resp.

\section{Discussion}

From the tables and figures it is clear that a uniform solution for the standardization of various neonatal bilirubin methodologies is very difficult to achieve. At least we can better understand now why there is so much variation with respect to accuracy and precision as shown by the surveys held in The Netherlands and Germany.

It is certainly valuable that candidate reference method exists for the determination of total bilirubin in serum. Because of the reasons mentioned by Doumas et al. a diazo procedure (3) was chosen. There is no reason to ignore the application of this technique in the neonatal field, although direct reading methods are very popular for neonatal analysis. The same holds true for bichromatic measurements with buffer dilution. It is understandable that commercial standard serum samples are used for these methods (tab. 1). However, as already mentioned, surveys point to a wide variation in bilirubin results.

Most of the commercial standards, (often called control sera with assayed values have a quoted diazo value with a certain range, the origin of which is very difficult to trace for the user. Therefore, it was worthwhile in our opinion to apply the "officially proposed" diazo method for these products. As can be seen from table 2 we found some differences between our reference method values and the values given by the manufacturer. We do not know whether these differences can be attributed to the lots we used in this study or to the diazo modification. In addition to the checks described under Materials and Methods we also determined the various bilirubin preparations with the Hertz technique; the values obtained with this method correlate well with the quoted values for the commercial products used by Hertz et al. in their study (7).

However, the reported differences mean that for direct reading, as described in table 3 , the results of the actual neonatal bilirubin determinations can show a wide variation. In a clinical situation this could mean that one hospital would take no special care, while another hospital would consider phototherapy or even exchange transfusion on the basis of the laboratory results. This is of course an unacceptable situation.

The question arises of how the candidate reference method can be applied in the neonatal field. There is no doubt that a correct calibration is valuable in improving the accuracy $(1,2,10)$. The same holds true for the application of the candidate reference method. The problem, however, is that the neonatal serum matrix differs in certain aspects from the adult serum matrix (protein composition, carotenoids). These differences may play a role when dealing with bichromatic measurements, so one has to consider the production of an "ideal" bilirubin standard preparation with neonatal serum. This seems to us a very difficult approach. Therefore the solution must be either more imperative or more pragmatic. Imperative by "banning" direct reading instruments or at least promoting the diazo procedure. Pragmatic, being the most elegant solution for the time being, by following the National Committee for Clinical Laboratory Standards (NCCLS) recommendations which implies the application of the Principal Assigned Value (PAV) and the System Specific Value (SSV) concept. This is already done by the Dade company in the neonatal field. The product sheet of the Dade 
Bilirubin Control contains data for the various bilirubin methodologies. Use of the target value given for the direct reading method and recalculation of the neonatal serum results gives a considerable improvement; instead of a difference of $30 \%$ between the reference and direct measurement values (tab. 3), the difference is now 16\% (not given in the table). Although this is an improvement, the situation is still not entirely satisfactory, because the product data are difficult to trace for the general user. However, in the absence of official recommendations, the manufacturer has to select his own policy.

Table 3 gives the impression that for direct reading measurements human serum is a better protein matrix than human albumin, notwithstanding the shortcomings mentioned before. This impression is based on the results obtained with the Dade Bilirubin-Control and our own albumin preparation.

The last part of the study concerned the calibration of the DuPont ACA. As explained above (see Results and fig. 1 and 2) we have a satisfactory calibration procedure for our own purpose. Expressed simply, we take the "wrong" (i.e. adult) samples for calibration, measure these with the well established Hertz method (for which we found a matrix effect, see fig. 2) and the result gives the right answer for neonatal samples as judged on the application of the reference method (fig. 1). Also with the calibration of the ACA we meet a problematic situation when considering commercial and home-made bilirubin preparations as can be seen in table 4. In this connection, it is remarkable that we found the largest deviations for the calibrating materials that were specially developed for use in the ACA (see addendum).

\section{References}

1. Blijenberg, B. G. \& Leijnse, B. (1980) J. Clin. Chem. Clin. Biochem. $18,27=30$.

2. Blijenberg, B.G., Brouwer, H.J., Roetering, H.A. \& Leijnse, B. (1984) J. Clin. Chem. Clin. Biochem. 22, $609-612$.

3. Doumas, B.T., Ǩwok-Cheun, P.P., Perry, B.W., Jendrzejezak, B., McComb, R. B., Schaffer, R. \& Hause, L. L. (1985) Clin. Chem. 31, 1779-1789. .

4. Blijenberg, B. G. \& Leijnse, B. (1979) J. Clin. Chem. Clin. Biochem. 17, 303 - 308 .

5. National Institute of Public Health (The Netherlands), Rapport nr. 378500001 (1986).

6. Perry, B. W., Doumas, B.T., Bayse, D. D., Butler, T., Co= hen, A., Fellows, W., Garber, C. C., Howell, B., Koch, T.,
At the moment we have no answer to this problem except the above mentioned NCCLS-concept or our own procedure. Maybe we are concerned here with a matrix effect for which Vink et al. have proposed an interesting and promising solution (8). Work is in progress now in trying to find a satisfactory explanation and solution for the standardization of neonatal bilirubin measurements.

Since direct reading instruments are simple to operate and look like push-button machines, the question may arise as to whether it is acceptable to use them on wards without control from the central laboratory (9). In our opinion they should not be used in that way. However, the central laboratory also needs further recommendations.

\section{Addendum}

A footnote to table 4 gives the recently improved data of the ACA Bilirubin Calibrator, which further confirm that a reference system is needed for both the commercial and the professional user.

\section{Acknowledgement}

We would like to thank

Dr. J.C. Koedam (Dutch Insitute of Public Health, Bilthoven) for providing the control materials.

Dr. H. Baadenhuysen (Dutch Quality Assessment Foundation, Nijmegen) for his help with the bilirubin survey questionnaire. Drs. C. P. Modder (Van Dam-Bethesda Ziekenhuis, Rotterdam) for his help in the collection of specimens.

Dr. G. Röhle (Deutsche Gesellschaft für Klinische Chemie, Bonn) for organizing a roundtable discussion on neonatal bilirubin.

Mrs. A.P. Copper-Staamer for her skillfull clerical assistance in preparing the manuscript.

Krishnamurti, S., Louderback, A., McComb, R. B., Miller, D., Miller, R.R., Rand, R. N. \& Schaffer, R. (1983) Clin. Chem. 29, 297-301.

7. Hertz, H., Dybkaer, R. \& Lauritzen, M. (1974) Scand. J. Clin. Lab. Invest. 33, 215-230.

8. Vink, C. L.J., Schuurman, W. \& Van Gansewinkel, R. (1986) Clin. Chem. 32, 1389-1393.

9. Harkness, R. A., Lawrence, C. R., Renshaw, A., Barr, I. C., Brown, S. S. \& Rinsler, M. G. (1983) Ann. Clin. Biochem. 20, 149-152.

10. Watkinson, L. L., St. John, A. \& Penberthy, L. A. (1982) J. Clin. Pathol. 35, 52-58.

11. National Institute of Public Health (The Netherlands) Rapport nr. 378507002 (1986). 
$-$

-

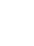

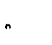

